\title{
Academética: Um Novo Método de Estudo Continuado sobre Ética Médica e Bioética
}

\author{
Academética: A New Method of Continuous \\ Study in Medical Ethics and Bioethics
}

\author{
Rodrigo Abensur Athanazio'; \\ Kleuber Moreira Lemos'; \\ Dayanne Costa Fonseca?: \\ Monaliza Santos da Cunha ${ }^{1}$; \\ Maria Ignez F. Melro Braghiroliz; \\ Alessandro de Moura Almeida'; \\ Geila Ribeiro Nuñez; \\ Ana Cláudia Nogueira Ramos': \\ Marcelo Campos Barbetta; \\ Almir Galvâo Bitencourtt; \\ Marina da Rocha Lordelo?: \\ Ivana Maria Rocha'; \\ Alana Santos Soares'; \\ Nedy Cerqueira Neves'; \\ Antônio Nery Filho ${ }^{3}$
}

WITRAS-CHAVE:

Hítica Médica:

Binética;

Princifitite Mories;

Educrição Continunda:

Eiluelanavs de Medicina.

TFY'-IIURDS:

Exhica. Medicul.

Binethics;

+ Morals:

Fiducation, Conanuiser;

Srudents, Medical.

atcebido $\mathrm{cm:} 05 / 0(1 / 2(1) 3$

kencaminhado em: 10)/09/2003

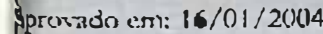

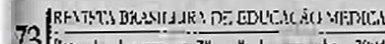

\section{RESUMO}

A consciência de que a prática médica deve estar fundamentada na postura ética dos profissionais leva à crescente importáncia de um ensino de ética continuado e aprofundado, que ressalte os vajores morais e humanos e o comprometimento social dos estudantes. Buscando adequar-se a esse novo paradigma, estudantes de Medicina da Universidade Federal da Bahia aceitaram a sugestāo da criaçăo, em novembro de 2000, de um grupo denominado Academética - Associaço de Acadêmicos para 0 Estudo da Ética Médica e Bioética. Os objetivos traçados pela equipe são: continuar o contato com o cmatevido da disciplina titica Médica, aprofundando e atualizando as discussoes acerca de Ética Médica e Bioética, e desenvolver trabalhos ligados a este assunto. As discussoes de temas sâo realizadas atraves do estudo de artigos, vdeas e estrmulo à participacao dos estudantes em congressos, palestras e afins. Desta forma, a Academética se constitui em mais una ferramenta para que os alunos durante a graduaca na faculdade de Medicina possam desenvolver o senso critico e conhecinnento acerca de assuntos que englobem a tética Médica e Biótica.

\begin{abstract}
The awareness that medical practice should be based on an ethical professional attitude has highlighted the growing importance of in-depth, continuing ethical education, emphasizing moral values and students' social commitment. Seeking to adjust to this new paradjgrn, in November 2000 medical students from the Federal University in Bahia, Brazil RFBA) Founded Academetica, the Academic Association for the Study of Medical Ethics and Bioethics. The objectives are to updare topics fiom the course on medical ethics and develop studies on these themes. Discussions are based on scientific articles, videos, and participation by students in congresses, conferences, etc. Academética thus provides additional tools to develop a critical approach towards Bioethics and Medical Ethics dusing medical studerts' undergraduate training.
\end{abstract}

\footnotetext{
'Acedernico de Medicina, membro da Academélica, Unioersidade Fademl do Bahia, Facuidads de Modicine, Saloador, Brasil.

Ofratmologista, Profasora Assistente da EBMSP, Professora Substituta, Universidaiz Federnt da Bahia, Faculdade de Medicina, Departaurento de Anitomia Patolggior e Medicina Legal, Saloador, Brasil.

' Psiquiatra. Professor Adjunto IV. Unioersidade Federal da Bahia, Feculdade de Meticina, Departamento de Anotonica Patológion e Meticina Lezal, Solkndor, Brasji.
} 


\section{INTRODUÇÃO}

Nāo existe na medicina nada mais clássico e moderno ao mesmo tempo como a ética médica e os temas discutidos pela bioética. Elas acompanham todos os passos da história da medicina e merecem extremo destaque já que exercem uma grande responsabilidade como guia de conduta dos médicos.

Atualmente, o conceito de ética médica vem aunentando o seu foco sobre o estudo formal e análise dos problemas éticos e morais encontrados na prática médica. Isto decorre do entendimento de que não basta um guia de condutas como o cơdigo de ética médica para orientar o comportamento dos profissionais desta área. Desta forma, falar em ética médica é falar em moral e em tomadas de decisōes que transcendem os aspectos puramente cognitivos que sāo tão valorizados dentro do meio médico.

Definir Bioética não é uma tarefa fácil, sendo alvo de trabalho de inúmeros estudiosos. Uma das mais recentes definiçōes de Potter ${ }^{3}$ trata a Bioética como uma nova ciência ética que combina humildade, responsabilidade e uma competência interdisciplinar, intercultural e que potencializa o senso de humanidade. Para Comte Sponville ${ }^{2}$ Bioética năo é uma parte da Biologia; é uma parte da Ética, é uma parte da responsabilidade humana; deveres do homem para com outro homem, e de todos para com a humanidade. Pode-se ainda buscar uma definição mais detalhada como a de de Reich $^{3}$ que diz ser o estudo sistemático das dimensōes morais - mcluindo visão moral, decisర̃es, conduta e políticas - das ciências da vida e atenção à saúde, utilizando uma variedade de metodologias éticas em um cenário interdisciplinar.

A medicina atual está marcada por um extraordinário avanço no conhecimento em todas as áreas, inclusive no campo da Bioética. É válido ressal tar que a Bioética é uma ciência "agregadora" que busca discutir e relacionar temas de âmbitos, outrora, considerados antagônicos, tais como as questōes técnico-científicas e as psico-sócio-filosóficas. Ela desempenha um papel extremamente relevante dentro da Medicina, palco constante de conflitos entre questōes que englobam as ciências naturais, sociais e exatas.

Desde 1971, quando Potter ${ }^{4}$ pela primeira vez introduziu o termo "bioethics", o número de trabalhos e pesquisadores preocupados com esse tema cresceu exponencialmente. Este fato parece ter sido decorrência da conscientização da necessidade de se discutir alguns temas de maneira mais abrangente e integralizada, podendo-se atingir os problemas em sua essência. Assim sendo, poder-se-ia suscitar reflexð̃es ou, até mesmo, soluçōes mais coerentes diante dos novos e ao mesmo tempo antigos paradigmas sociais. De qualquer forma, esses estudos ainda são insuficientes diante da evolução descontrolada de avanços no âmbito técnico-científico e das desigualdades sociais ${ }^{5}$. A bioética surge em um momento em que $o$ avanço da ciência depara-se com a possibilidade de trazer conseqüências incalculáveis para o bem estar humano ${ }^{6}$ Desta forma, a bioética surge como um grito de esperança $e$, como diria Potter", uma ponte para o futuro.

A ética médica, entretanto, tem sua origem nos primórdios da medicina. A preocupação com a moral e o respeito pela vida são temas abordados desde o juramento de Hipócrates há mais de 2500 anos. O médico está submetido, em qualquer lugar do mundo, a normas éticas pré-estabelecidas que orientam a conduta médica nas mais diversas atividades que este possa desempenhar. Contudo, apesar de sua importância, apenas recentemente passou a ser incluída como disciplina no currículo médico de graduação ${ }^{7}$.

Diante dessa realidade, torna-se primordial uma atençāo especial aos estudantes de medicina que, durante sua formaçâo acadêmica, devem adquirir uma gama de conhecimentos técnicos, mas, principalmente, conhecimentos e valores éticos que nortearão toda a sua vida profissiona!. Os principais objetivos do ensino de ética médica são ${ }^{8.9}$ : a) ensinar a reconhecer os aspectos éticos e humanisticos da carreira médica; b) permitir a investigação e afirmaçāo dos preceitos morais individuais e profissionais; c) propiciar a fundamentação de un conhecimento geral acerca de filosofia, direito e sociologia; d) permitir a aplicação deste conhecimento no pensamento clínico; e) fornecer auxilio no desenvolvimento das habilidades integradas que são necessárias para a aplicação destes conhecimentos no tratamento das necessidades clínicas humanas.

As próprias faculdades estāo percebendo a importância desse tema e diversos curriculos estão sendo al terados com 0 intuito de dar mais ênfase a assuntos relacionados à Ética Médica e Bioética. Além disso, muitas outras entidađes tam. bém estāo preocupadas com esse tema, como pode ser visto com a apresentação do consenso do Reino Unido sobre o ensino de ética médica ${ }^{8}$. No Brasil, assim como em diversos outros países ${ }^{10,11}$, o ensino de ética estava confinado a um pequeno espaço de tempo dentro do currículo da graduação, muitas vezes não chegando a configurar uma disciplina. Acompanhando a tendência mundial, as faculdades brasilciras vêm incluindo uma disciplina própria no seu currículo para o ensino dos valores morais relacionados à medicina, antes restritas a uma parte da ementa de Medicina Legal ${ }^{12,13}$

Todavia, o ensino de ética médica e bioética está longe do ideal. Existe, atualmente, uma tendência deste assunto ser lecionado de forma integrada e contínua durante todo o curso de Medicma ${ }^{13,14,15}$. Existem assuntos que merecem ser apro- 
fundados e dependem do grau de maturidade do aluno, que é mutável durante os anos de graduação. Desta forma, não há um momento ideal no qual os assuntos de deontologia e diceologia médica devessem ser ministrados. Necessita-se de uma reforma curricular que contemple, em todos os níveis da formação discente, aspectos éticos que são preponderantes para uma prática profissional saudável ${ }^{36,17}$.

Existem diversos modelos para o ensino desse tema. Porém, nenhum, até hoje, mostrou-se significativamente superior aos demais ${ }^{10,13,14,18,19}$. Na maioria dos modelos, o problema não está na metodologia, mas na carga horária e tempo de contato do aluno com a disciplina. Uma alternativa para esse problema seriam os cursos extracurriculares, que poderiam suprir algumas deficiências do currículo mínimo da graduação. Apesar de não conseguir atingir todos os acadêmicos, seria um referencial para o contato permanente com os assuntos de deontologia e diceologia médica. Diante do panorama atual, esses cursos extracurriculares poderiam servir como medida paliativa a uma defasagem do currículo médico. Entretanto, seu papel seria ainda mais importante após uma reforma curricular que passasse a incluir o ensino de ética médica de forma integrada. Neste caso, sua função primordial passaria a de constituir um centro de referência para aprofundamento, promoção de discussð̃es e pesquisas na área de ética médica e bioética.

O objetivo desse trabalho é apresentar a experiéncia de um novo modelo de estudo de ética médica e bioética denominado Academética - Associação dos Acadêmicos de Medicina para o estudo da Ética Médica e Bioética. Inserido dentro do contexto da Faculdade de Medicina da Universidade Federal da Bahia - Brasil, esse grupo visa promover o maior contato dos acađêmicos interessados nesses temas através de grupos de pesquisa, fóruns, debates e participação em eventos cientificos.

\section{Histórico e Contexto Institucional}

Durante muitos anos, os acadêmicos de medicina da Universidade Federal da Bahia foram apresentados aos direitos e deveres (deontologia e diceologia) inerentes à categoria médica em apenas duas aulas, totalizando não mais de quatro horas durante o curso de Medicina Legal e em torno do décimo semestre. Com a reforma universitária nos anos setenta, foram extintas as "turmas", e os alunos passaram a construir percursos sem maiores laços de companheirismo e nenhuma identidade grupal. Há de se imaginar o quanto ficava por dizer aos estudantes sobre as regras que deveriam nortear a conduta médica ao longo da vida de cada profissional.

A bem da verdade, alguns professores do departamento como a Professora Maria Theresa Pacheco sempre desejaram ampliar este ensino, esbarrando nos imperativos acadêmicos até 1995, quando convenceu as instâncias administrativas da Faculdade de Medicina da importância de ser atribuído à Ética Médica um espaço semestral e, mais do que isso, trazê-la para o primeiro semestre do curso médico, antecipando-se aos desvios e prevenindo-os, para nāo remediar. Diversos temas de interesse ético foram introduzidos no programa, a exemplo da eutanásia, publicidade médica, erro médico, relação médico-paciente e AIDS.

Em 1997, o o Plenário do Conselho Regional de Medicina da Bahia (CREMEB) ${ }^{20}$ aprovou, por pedido da Mesa Diretora, a solicitação para que o curso de Etica Médica ocorresse nas dependências do Conselho, lugar tradicionalmente visto com temor e desamor, em razão de sua função judicante, inaugurando, assim, frutuosa parceria desta instituiçāo com a academia. Deste modo, os jovens estudantes, longe de temer, passaram a ídentificar o Conselho como lugar de defesa da prática médica honesta e de garantia de uma ética indiscutivel, como indica a etimologia da palavra grega "ethos" - um modo de ser, diversa, mas não distanciada da moral, cuja raiz latina "mos" ou "moris", significa costumes, isto é, conjunto de normas ou regras adquiridas por hábito. Desde então, apoiado nos princípios da Bioética e orientados pelo Código de Ética Médica (CEM), resultado do trabalho dos Conselhos Regionais e consubstanciado pelo Conselho Federal de Medicina, o ensino da Ética Médica na Faculdade de Medicina da Universidade Federal da Bahia, tem convocado os alunos a serem sujeitos de seu aprendizado.

Com a mudança, a disciplina passou a ser ministrada no primeiro semestre, contendo a presença de dois professores específicos para o ensino da Ética Médica e Bioética. A carga horária semestral $\in$ de 45 horas, correspondendo a uma aula de duas horas por semana. As aulas são baseadas em seminários apresentados pelos próprios alunos que abordam temas do Código de Ética Médica. Em cada aula, existe a presença de convidados que auxiliam na realização do debate após a apresentação.

Mais recentemente, foi adotada a estratégia de associar o nome de um filósofo a cada capítulo do CEM, trazendo de volta o gosto pela filosofia e pondo em evidência as bases indispensáveis à compreensão das regras éticas. Vale salientar o acervo de comentários sobre o CEM, constituído a partir da análise crítica realizada pelos alunos e que será importante no momento da revisão do atual Código. Finalmente, uma iniciativa importante, ocorrida originalmente no segundo semestre letivo de 2002, foi a escolha, feita pelos próprios alunos, de artigos do CEM considerados mais importantes e indispensáveis ao conhecimento do grande público. Os artigos 
acompanhados de respectivos comentários são apresentados sob forma de 'cartilha', distribuída à comunidade ao longo de uma caminhaḍa. O objetivo dessa ação é extrapolar os limites acadêmicos e propiciar aos discentes um maior contato com a populaçāo e suas demandas.

E neste contexto que surge a Academética com o intuito de dar continuidade à preocupaçāo do aprendizado dos temas de Ética Médica e Bioética e buscando complementar as atividades desenvolvidas pela disciplina de Deontologia e Diceologia Médica durante o restante do curso de medicina.

\section{Modelo de Trabalho}

Participam do grupo graduandos em medicina que conclứram a disciplina Deontologia e Diceologia Médica (Ética Médica), sendo a participação de caráter voluntário e declarado no início de cada semestre letivo, sujeito, portanto, a renovação constante. Hả a participação de alunos de diversos semestres letivos, que contribuem nas discussōes com diferentes experiências pessoais. Não há determinação de número mínimo ou máximo de alunos, ficando as atividades divididas entre aqueles que se declaram atuantes durante o semestre.

São realizadas reuniões quinzenais com 2 a 3 horas de duração, na sede do Conselho Regional de Medicina da Bahia (CREMEB), tendo o apoio desta instituição, e sob orientação dos professores da disciplina Etica Médica. Altemadamente, as reuniões têm a finalidade de 1) efetuar os trabalhos em andamento ou 2) promover o estudo de temas de Ética e Bioética, através da discussảo de vídeos, artigos, textos, revistas e palestras disponibilizados com antecedencia aos participantes.

Para a organização dos trabalhos, a Academética é dividida em subgrupos. Entretanto, todas as decisões importantes relacionadas a estas atividades são levadas para discussão com todos os integrantes. No caso de existirem diferentes sugestð̌es, estas são votadas, prevalecendo a decisão da maioria. Nestas reuniōes são também discutidos novos projetos e seus métodos de execução.

As reuniões de discussảo de Bioética visam ao aprofundamento do conhecimento e do senso crítico para assuntos desta área. São disponibilizados via internet artigos ou textos sobre o tema previamente definido. $\mathrm{Ha}$, ainda, a possibilidade de debate sobre filmes ou vídeos de palestras recomendados. $\mathrm{O}$ grupo discute o conteúdo destes materiais, objetivando, sempre que possível, chegar a um consenso das idéias abordadas. Eventualmente, há a participação de especialistas que relatam seus trabalhos ou experiências, enriquecendo ainda mais as discussōes.

A organizaçāo das atividades conta com a atuação de uma diretoria formada por 4 alunos que estejam participando das reuniões assiduamente e cuja formação tem uma duração indeterminada, a depender da vontade e disponibilidade dos seus componentes. Dois dois componentes da diretoria têm uma função administrativa, sendo responsáveis pelo agendamento, organização e condução das reuniōes, além de coordenação dos subgrupos de trabalho. A outro aluno cabem funções relacionadas à informática, como cadastramento dos componentes, organização do grupo de discussāo, arquivo de mensagens, textos e atas das reuniōes. Por fim, ao tesoureiro cabe a viabilização da participação do grupo em congressos e demais eventos, buscando recursos financeiros através da doação de instituições médicas, além da possível contribuição dos próprios membros. Ao final de cada mandato da diretorias, os cargos são passados para alunos mais novos no grupo, mas que já estejam participando das reuniões há no mínimo seis meses.

A Academética dispōe de um grupo de discussão via internet, através do qual são disponibilizados os textos para discussão, agendamento de reuniōes gerais ou dos subgrupos além da froca de notícias, informações e mensagens em geral.

\section{Projetos}

Desde a sua fundação, os projetos seguintes se delinearam diante da preocupação com os impactos da má prática médica na sociedade. Visam também adquirir, aprofundar e gerar conhecimentos acerca de Ética Médica e Bioética por parte dos seus integrantes, contudo sempre cientes da importância da difusão do conhecimento produzido e/ou discutido para o resto da comunidade acadêmica. Até o presente momento, já foram concluídos três projetos.

Foi desenvolvido o Código de Ética dos Estudantes de Medicina (CEEM) da UFBA. Este instrumento foi embasado no formato consagrado do Código de Ética Médica do Brasil e em outras experiências acadêmicas de códigos estaduais de Ettica Médica para estudantes de Medicina, com respectivas complementaçōes para melhor adequâ-lo à realidade local. Apresenta caráter recomendativo e tem por objetivo estimular a discussāo do comportamento ético do estudante de medicina. Visa consolidar a formação moral do futuro médico e por isso fornece ao estudante as normas e regras de conduta fundamentais para o relacionamento diário com professores, colegas, pacientes e familiares. Consta de preâmbulo, nove capitulos e disposições gerais. Aborda temas tais como: atos médicos praticados por estudantes de medicina; direitos, deveres e limitações do estudante; relação com pacientes, professores, profissionais de saúde, colegas e instituiçòes; segredo médico e; participação do estudante em pesquisa e publicação de trabalhos científicos. 
Foi realizada, também, uma pesquisa intitulada "O que os estudantes e professores da Faculdade de Medicina da UFBA sabem e dizem sobre Ética Médica e seu ensino". Acrença de que a formação médica contribui para a crise na identidade médico-paciente e a ausência de estudos a este respeito foram as motivações para a realização dessa pesquisa. Este trabalho realizou um estudo sobre o conhecimento do Código de Ética Médica (CEM), a freqüência de atualização em Etica Médica e Bioética e suas fontes, e a importância atribuída a estes temas entre os alunos e professores médicos da Faculdade de Medicina (FAMED) da Universidade Federal da Bahia (UFBA). Os resultados desse trabalho encontram-se em processo de publicação.

A Academética também participa, a convite do diretor da FAMED-UFBA, do jornal virtual da Faculdade de Medicina da Universidade Federal da Bahia. Trata-se de um espaço reservado no E-FAMED, jornal virtual de publicação mensal desta faculdade, para que possa veicular notícias sobre questōes atuais a respeito de Ética Médica e Bioética. Os assuntos abordados incluem trabalhos desenvolvidos pelo grupo de pesquisa, questōes atuais sobre Bioética e esclarecimentos sobre o Código de Etica Médica.

Dois novos projetos de pesquisa estão em andamento. Um aborda a questão do ensino de Ética Médica dentro da Faculdade de Medicina e outro sobre a prática médica não supervisionada de estudantes em estágios não curriculares.

O primeiro projeto (Formação e implementação de uma rede integrada de ensino de Ética Médica e Bioética na FAMED-UFBA) foi idealizado visto que o modelo clássico representado pela disciplina de Deontologia e Diceologia Médica está se mostrando insuficiente para atender satisfatoriamente a formação humanística do acadêmico de Medicina. Além disso, considera-se que o programa educacional nas escolas médicas deva promover uma interação com todas as disciplinas ao longo do curso, tornando-se necessária a identificação de professores capazes de introduzir ou fomentar a discussão ética e bioética nos diversos momentos em que as dúvidas ou situações reais ocorrerem. Nesse âmbito, a Academética desenvolve esse projeto com objetivo de identificar professores capazes de atuar dentro de diferentes disciplinas, funcionando como pontos de referência para discussão de problemas éticos que estejam surgindo durante aquele determinado momento do curso.

As diferentes visões do estudante de medicina sobre a prática médica não supervisionada é a outra linha de pesquisa desenvolvida atualmente pela Academética. A alta prevalência da prática médica realizada por estudantes de medicina sem a devida supervisão tem chamado a atençăo tanto no âmbito acadêmico como nos conselhos regionais de medicina. Diante da dimensão e repercussão social que este fato apresenta, cabe conhecer a realidade que impulsiona os jovens estudantes a essa prática e, particularmente, a percepçāo que estes têm deste ilícito ao longo de toda graduaçăo.

O compromisso social também é uma questāo muito discutida dentro do grupo. Desta forma, um dos objetivos da Academética é criar maneiras para passar informaçǒes relevantes sobre os temas debatidos em reuniōes para a sociedade. Ao fim de cada semestre, o grupo participa colaborando com a disciplina de Deontologia e Diceologia Médica da FAMED-UFBA em atividades que almejam difundir os direitos e deveres do médico presentes no CEM. O intuito principal é permitir que os pacientes tenham conhecimento apropriado das normas às quais esses profissionais estăo submetidos, para que possam melhor entender os seus direitos.

Alguns projetos ainda estão sendo discutidos para serem postos em prática. Um deles trata-se da promoção de fóruns e/ou seminários para discussão e aprofundamento de temas relacionados à Ética Médica e Bioética, visando atingir principalmente os graduandos de medicina e outras áreas. O objetivo principal dessa atividade é estimular a participação discente em eventos que abordem questōes éticas atuais como a discussão da Bioética social e tecnológica.

\section{Conclusão}

O ensino de Ética Médica depara-se com inúmeros desafios que tangem aspectos que abordam desde a formação de docentes capacitados como as técnicas de ensino. De qualquer forma, esses desafios merecem atenção e é função da Faculdade de Medicina assumir a responsabilidade, juntamente com os alunos e professores, para tentar solucioná-los. Novas formas de ensino e medidas de incentivo ao estudo de casos-problema que abordem temas sobre Ética Médica e Bioética devem ser criados a fim de se melhorar o ensino desta disciplina que, indubitavelmente, é uma das mais importantes dentro do currículo médico de graduação.

O modelo da Academética não pretende esgotar e contemplar todos os objetivos de um modelo ideal de ensino de ética médica. Almeja, entretanto, servir como mais uma ferramenta para que os alunos durante a graduação na faculdade de medicina possam desenvolver o senso crítico e conhecimento acerca destes assuntos. Desta forma, pretende-se alcançar o objetivo da formação de médicos não apenas competentes tecnicamente, mas também com bom embasamento moral e humanístico. Por fim, espera-se que o impacto destas açōes não se restrinj̧am apenas ao âmbito acadêmico, todavia alcance o próprio modelo social. 


\section{REFERÊNCLAS BIBLIOGRAFICAS}

1. Potter VR. Palestra apresentada em vídeo no IV Congresso Mundial de Bioética. Tóquio/Japão: 4 a 7 de novembro de 1998. O Mundo da Saúde 1998;22(6):370-374.

2. Comte Sponville A. Petit traité des grandes vertus. Paris (FR): PUF,1996. (Collection Perspectives Critiques).

3. Reich WT. Encyclopedia of bioethics. New York: Macmillan, 1995.

4. Potter VR Bioethics: bridge to the future. [s.l.]: Englewood Cliffs; Prandice-Hall, 1971.

5. Neitzke G. Teaching Medical Ethics to Medical Students: moral, legal, psychological and philosophical aspects. Med Law 1999; 18:99-105

6. Nicholas B. Power and the teaching of medical ethics. I Med Ethics 1999; 25(6):1-8

7. GlickS. The teaching of medical ethics to medical students. J Med Ethics 1994; 20:239-43

8. Goldie ]. Review of ethics curricula in undergraduate medical education. Med Educ 2000; 34:108-19

9. Benatar S. Teaching medical ethics. Q J Med 1994; 87:75967

10. Lovett L, Seedhouse D. An innovation in teaching ethics to medical students. Med Educ 1990; 24:37-41

11. Fox E, Robert M, Arnold M, Brody B. Medical ethics education: past, present and future. Acad Med 1995; 70(9):761-9

12. Siqueira J, Sakai M, Eisele R. O ensino de ética no curso de Medicina: a experiência de Universidade Estadual de Londrina (UEL). Bioética 2002; 10(1):85-95
13. Grisard N. Ética Médica e Bioética: a disciplina em falta na graduaçāo médica. Bioética 2002; 10(1):97-114

14. Goldie J, Schwartz L, McConnachie A, Morrison J. The impact of three years' ethics teaching, in an integrated medical curriculum, on students proposed behaviour on meeting ethical dilemmas. Med Educ 2002; 36:489-97

15. D’avila R. É possível ensinar Ética Médica em um curso formal curricular? Bioética 2002; 10\{1\}:115-26

16. Parker M, Price D, Harris P. Teaching of medical ethics: implications for an integrated curriculum. Med Educ 1997; 31:181-7

17. Perkins $\mathrm{H}$, Geppert $\mathrm{C}$, Hazuda $\mathrm{H}$. Challenges in teaching ethics in medical schools. Am J Med Sci 2000; 319(5):273-8

18. Hart C. From innocence to experience: teaching medical ethics to medical students. J Relig Health 1995; 34(1):55-60

19. Tysinger J, Klonis L, Sadler J, Wagner J. Teaching ethics using small-group, problem-based learning. J Med Ethics 1997; 23:315-8

20. Conselho Regional de Medicina do Estado da Bahia. Ata da $358^{\sharp}$ Sessão Plenária ordinária do Conselho Regional de Medicina do Estado da Bahia. Salvador (BA): CREMEB, out., 1998

\section{Endereço para Correspondência:}

Rodrigo Abensur Athanazio

Rua Ceará 853/1503

CEP: 41830-450 - Pituba; Salvador - BA

E-mail: rodrigoaa@bol.com.br 